\section{Spinal decompression sickness with delayed onset, delayed treatment, and full recovery}

Decompression sickness is caused by nitrogen bubbles formed in the body of divers and people working with compressed air who leave a compressed environment too fast. The bubbles most commonly afflict the joints, skin, brain, spinal cord, and lungs. Decompression sickness, if untreated, may cause permanent functional damage and is potentially fatal. We report an unusual case of decompression sickness affecting the brain and spinal cord in which neurological symptoms and signs first appeared five hours after the dive. Symptoms were partially relieved by oxygen, dextran 40 , and dexamethasone but disappeared fully only during hyperbaric treatment.

\section{Case report}

A 20 -year-old healthy male diver worked at 20 metres for 40 minutes and ascended with one three-minute decompression stop at three metres. Two hours later he complained of headache, sore throat, and malaise, and five hours later of pain in the left knee and left elbow, headache, and confusion.

On examination his temperature was $38.5^{\circ} \mathrm{C}$ and a mild follicular tonsilitis was found. There were no other abnormalities. Two hours later sensory loss in the right thigh, mild paraparesis, and loss of sensation around the anus developed. He received $20 \mathrm{mg}$ dexamethasone intravenously, $500 \mathrm{ml}$ dextran 40 , and sodium lactate (Hartmann's solution); oxygen was given by mask. Two hours later he was admitted to the Israeli Naval Hyperbaric Institute fully conscious and co-operative but unable to stand. Neurological examination showed hypoaesthesia in the L3 dermatome on the right, patellar reflex weak bilaterally, Achilles reflex normal bilaterally, abdominal reflexes missing, and severe paraparesis. Laboratory findings were normal, as were findings on chest and spinal radiography and electrocardiography. He was put into a recompression chamber and compressed to 18 metres breathing $100 \%$ oxygen (according to US Navy table No 6, (figure)). After 35 minutes he showed signs of improvement. After three hours 20 minutes at a depth equivalent to nine metres neurological examination showed no abnormalities.

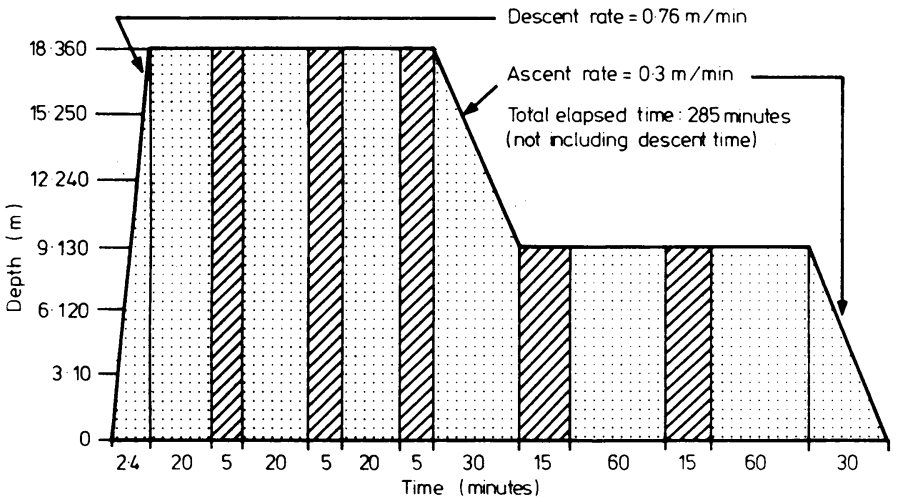

US Navy therapeutic recompression table 6 (reserved for severe decompression sickness). Stippled areas represent periods of breathing oxygen; hatched areas represent periods of breathing air.

\section{Comment}

The unusual characteristics of this case were the long delay preceding the onset of symptoms ${ }^{1}$ and the rapid and complete relief of symptoms on recompression despite the delay in starting treatment. The onset of spinal symptoms was probably facilitated by dehydration owing to fever, with resultant haemoconcentration and high viscosity and coagulability. So-called "silent bubbles" exist in the body of a diver even after dives made within accepted limits. Small numbers of bubbles are usually cleared in the lungs without producing symptoms. The bubbles may, however, be coated with thrombocytes. ${ }^{2}$ Aggregation of other blood elements follows, and vessels are progressively occluded by clots surrounding bubbles. ${ }^{3}$ Venous drainage of the spinal cord is in the form of a large, valveless venous lake in which the flow is normally sluggish and therefore vulnerable to obstruction by bubbles. ${ }^{4}$

Our patient was treated with oxygen, dexamethasone, and dextran 40. Rehydration was achieved with sodium lactate. Normobaric oxygen enhances dissolution of bubbles ${ }^{5}$; dexamethasone helps relieve oedema in the brain and spinal cord; dextran inhibits aggregation of thrombocytes and improves microcirculation; and sodium lactate expands blood volume and thus improves circulation and helps to relieve ischaemia and mobilise trapped bubbles. Recompression to $283.7 \mathrm{kPa}(2.8$ atmospheres) diminishes bubble size and thus relieves circulatory obstruction. Oxygen at high pressure improves oxygenation of ischaemic tissue and relieves oedema.

Hyperbaric treatment is the primary and specific treatment for decompression sickness, even when there is considerable delay after the accident. Pharmacotherapy may be of benefit. The prognosis of paralysis due to decompression sickness is poor without treatment.

${ }^{1}$ Dewey AW. Decompression sickness, an emerging recreational hazard. $N$ Engl f Med 1962;267:759-65.

${ }^{2}$ Philp RB, Inwood MJ, Warren BA. Interactions between gas bubbles and components of the blood: implications in decompression sickness. Aerospace Medicine 1972;43:946-53.

${ }^{3}$ Cockett ATK, Pauley SM, Zehl DN, et al. Pathophysiology of bends and decompression sickness. Arch Surg 1979;114:296-301.

${ }^{4}$ Hallenbeck JM, Bove AA, Elliott DH. Mechanisms underlying spinal cord decompression sickness. Neurology 1975;25:308-16.

${ }^{5}$ Grulke DC, Hills BA. Experimental cerebral air embolism and its resolution. In: Shilling CW, Beckett MW, eds. Underwater physiology VI: proceedings of the sixth symposium on underwater physiology. Bethesda, Maryland: Federation of American Societies for Experimental Biology, 1978:587-94.

(Accepted 23 December 1981)

Israeli Naval Hyperbaric Institute, PO Box 8040, Haifa, Israel

P HALPERN, MD, physician

A GREENSTEIN, MD, physician

Y MEL.AMED, MD, director

Spinal Unit, Hadassah University Hospital, Ein Kerem, Jerusalem, Israel

J Y MARGULIES, MD, resident physician

G C ROBIN, FRCS, head of unit

\section{Prolactin-like immunoreactivity in human small-intestinal mucosa}

Several peptide hormones are present in both the brain and the gastroenteropancreatic endocrine system. ${ }^{1}$ The possibility that prolactin is another "brain gut" peptide was suggested by the persistently raised serum concentrations of prolactin $(>1000 \mathrm{mU} / \mathrm{l})$ found in some patients with coeliac disease ${ }^{2}$ with no other obvious cause for the hyperprolactinaemia. ${ }^{3} \mathrm{We}$ sought prolactin-like immunoreactivity in small-intestinal biopsy specimens using a simple technique for showing gastroenteropancreatic endocrine cells.

\section{Methods and results}

Small-intestinal biopsy specimens were obtained with a Watson capsule from the distal duodenum and the proximal jejunum in patients undergoing investigation for possible coeliac disease. The specimens were orientated on monofilament nylon gauze with the luminal surface uppermost, placed immediately in modified Susa fixative, and examined under a dissecting microscope (modified Susa fixative consisted of $76 \mathrm{mmol}(12.5 \mathrm{~g})$ trichloroacetic acid, $43 \mathrm{mmol}(2.5 \mathrm{~g})$ sodium chloride, $100 \mathrm{ml} 40 \%$ formaldehyde, and $25 \mathrm{ml}$ glacial acetic acid, made up to $500 \mathrm{ml}$ with distilled water). The period of fixation varied from a few hours to two weeks with no resultant loss in peptide hormone immunoreactivity.

The fixed tissue was washed in several changes of $70 \%$ ethanol and processed as per routine paraffin technique. Serial $5 \mu$ sections were cut from paraplast-embedded tissues, dewaxed, and rehydrated in phosphatebuffered saline $\mathrm{pH} 7 \cdot 4$ with resultant unmasking of immunoreactive sites. Sections were stained using an indirect immunofluorescence technique with rabbit antihuman prolactin as primary antibody (Tenovus Cancer Research Laboratories, Cardiff) and swine antirabbit IgG conjugated with fluorescein isothiocyanate as secondary antibody. The specificity of this antibody was examined with respect to human growth hormone and adrenocorticotrophic 